\title{
EN TORNO AL AMICUS CURIAE
}

\section{VÍCTOR BAZÁN*}

\begin{abstract}
Resumen
La Corte Interamericana de Derechos Humanos es consciente de que los jueces y tribunales internos están sujetos al imperio de la ley y, obligados a aplicar las disposiciones vigentes en el ordenamiento jurídico. Pero cuando un Estado ha ratificado un tratado internacional como la Convención Americana, sus jueces, están sometidos a su cumplimiento. El Reglamento de la Corte Interamericana de Derechos Humanos reformado parcialmente y renovado en vigor, en su artículo 2.3. define el término amicus curiae como "la persona ajena al litigio y al proceso que presenta a la Corte razonamientos en torno a los hechos contenidos en la demanda o formula consideraciones jurídicas sobre la materia del proceso, a través de un documento o de un alegato en audiencia". Por lo que tienen un importante valor para el fortalecimiento del sistema interamericano de protección de los derechos humanos, a través de reflexiones aportadas por miembros de la sociedad, que contribuyen al debate y amplían los elementos de juicio con que cuenta la Corte.
\end{abstract}

En síntesis, el amicus curiae es un instrumento plausible y digno de ser explorado para tonificar el debate judicial ampliando los márgenes de deliberación, por medio de argumentos públicamente analizados, aportar a la defensa y la realización de los derechos humanos y contribuir a la elaboración de sentencias razonables y generadoras de un grado sustentable de consenso en la comunidad.

Palabras clave: Amicus curiae - Derechos humanos.

\begin{abstract}
The Inter-American Court of Human Rights is aware that judges and domestic courts are subject to rule of law and forced to apply provisions in force in their body of laws. But, when a State has ratified an international treaty such as the American Convention, the judges are forced to observe them.

Article 2.3 of the applicable Regulations of the Inter-American Court of Human Rights, partially reformed and renewed, defines the term amicus curiae as "the person strange to the dispute and proceeding who offers the Court ideas about the events contained in a lawsuit or formulates juridical considerations on the matter of the proceeding through a document or pleading in a hearing". Therefore, they have a significant value for the strengthening of the interAmerican system for the protection of human rights, through reflections
\end{abstract}

\footnotetext{
* Profesor de la Facultad de Derecho y Ciencias Sociales, Universidad Católica de Cuyo (San Juan, Argentina). Miembro Titular de la Asociación Argentina de Derecho Constitucional.
} 
provided by members of the society, which contribute to the debate and extend the facts available to the Court.

In summary, an amicus curiae is a plausible instrument which should be explored in order to invigorate the judicial discussion and extend deliberation margins, through publicly analyzed arguments, contributing to human rights defense and performance and contributing to the rendering of reasonable judgments resulting from a sustainable degree of agreement among the community.

Key words: Amicus curiae - Human rights

\section{Sumario}

1. Consideraciones previas. 2. Breve aproximación a los lineamientos centrales del instituto. 3. Génesis y propagación de la figura. 3.1. Origen y diseminación hacia ámbitos de habla o influencia inglesas. 3.2. Su uso en instancias iusinternacionales. 3.3. Utilización del instituto por algunos órganos de clausura de la justicia constitucional en Latinoamérica. A. Argentina. B. Perú. C. Brasil. D. México. 4. Lineamientos generales del amicus curiae. 4.1. Mutación de su rol. 4.2. Su importancia cuando deben resolverse jurisdiccionalmente cuestiones jurídica y axiológicamente dilemáticas. 5. Otro espacio trascendente en el que el aporte de amici se hace particularmente perceptible. 5.1. Contexto. 5.2. L intervinculación de los controles de constitucionalidad y convencionalidad. 5.3. Una potencialmente valiosa contribución argumental en los ámbitos interno e internacional. 6. Observaciones de cierre.

\section{CONSIDERACIONES PREVIAS}

Sin pretensión alguna de exhaustividad, en el presente trabajo nos proponemos realizar algunas reflexiones generales sobre el amicus curiae ("amigo del tribunal" o "asistente oficioso") y ponderar su eventual incidencia o utilidad en pro de elevar la cotización cualitativa del debate judicial.

En el curso de este breve emprendimiento propositivo, y luego de intentar un acercamiento conceptual, enfocaremos en primer término la génesis de la figura, su trasvasamiento al derecho inglés y posterior canalización hacia otros ámbitos geográficos donde impera el Common Law ${ }^{1}$, además de su utilización en instancias internacionales y el paulatino empleo que de la misma llevan adelante los órganos de cierre de la justicia constitucional en ciertas latitudes del arco latinoamericano.

Posteriormente, describiremos de manera sucinta la metamorfosis que sufriera el instituto desde su configuración primigenia hasta la actualidad y, adelantando nuestra opinión, nos detendremos en las interesantes perspectivas y potencialidades funcionales que suministra para brindar mayor transpa- 
rencia a las decisiones jurisdiccionales de interés público, encumbrarse como un vehículo para democratizar el debate judicial y, por extensión, vigorizar la garantía del "debido proceso", que involucra - inter alia - la emisión de sentencias razonadas, justas y jurídicamente sustentables, misión eminente en cabeza de los jueces, cuya legitimidad en buena medida se asienta en la razonabilidad de sus pronunciamientos.

Es que en este ámbito, como en general sucede en todos los espacios jurídicos relevantes, la labor de la magistratura judicial debe estar recorrida axiológicamente por la pauta de la razonabilidad, cuya forma de ser percibida y concebida ha mudado, pasando - en palabras de Zagrebelsky - de requisito subjetivo del jurista a requisito objetivo del derecho ${ }^{2}$.

Retomando el anuncio del itinerario que proyectamos transitar, advertimos que en el tramo final del nudo del trabajo - y de modo inmediatamente anterior al epílogo - no estarán ausentes ciertas apreciaciones en torno al aporte que la figura puede brindar en un ámbito especialmente significativo: el de la aplicación, por los magistrados locales, del derecho internacional de los derechos humanos, sin soslayar su paralela contribución a la labor de los propios jueces de tribunales internacionales; perfil funcional de una magnitud tal que invita, al menos, a desterrar visiones que descarten a priori el instituto que concita aquí nuestra atención.

\section{BREVE APROXIMACIÓN A LOS LINEAMIENTOS CENTRALES DEL INSTITUTO}

En presentación casi rudimentaria, y para contextuar el análisis que a continuación realizaremos, puede decirse que la participación procesal del amicus curiae supone la presentación en un proceso de un tercero que interviene aportando una opinión fundada que puede resultar relevante para la resolución de un litigio en el que se debatan cuestiones socialmente sensibles.

Ese tercero, por tanto, no reviste calidad de parte ni mediatiza, desplaza o reemplaza a estas; debe ostentar un interés justificado en la decisión que pondrá fin al pleito en el que se presenta; es preciso que muestre reconocidas competencias y versación en la cuestión debatida; su informe no constituye un dictamen pericial, y la actuación que despliega no devenga honorarios ni tiene efectos vinculantes para el tribunal ante el que comparece.

Su condición de amigo del tribunal se materializa a través de una actividad de alegación sobre el tema que constituye el objeto de una decisión judicial, 
tarea que realiza como persona ajena a la relación jurídico-procesal ${ }^{3}$ en causas que, como anticipábamos, ostenten trascendencia institucional o interés público.

\section{GÉNESIS Y PROPAGACIÓN DE LA FIGURA}

\subsection{Origen y diseminación hacia ámbitos de habla o influencia inglesas}

Los primeros antecedentes del instituto pueden ubicarse en el derecho romano ${ }^{4}$ y luego en el derecho inglés, siendo posteriormente receptado y desarrollado en el contexto jurídico norteamericano y en otros países de habla o influencia inglesas.

Así, en relación con estos últimos, pueden computarse la Rule 18 de la Suprema Corte de Justicia de Canadá; la Orden IV, par. I, de las Reglas de la Suprema Corte de India; la Rule 81 de la High Court de Nueva Zelanda y, en Australia, el precedente 'Lange vs. ABC' [S 108/116] $]^{5}$.

Por su parte, en EE.UU. las vigentes "Rules of the Supreme Court", adoptadas el 17 de julio de 2007 y operativas desde el 1 de octubre del mismo año, aluden reiteradamente al amicus curiae, por ejemplo, centralmente en la regla 37, donde abunda en detalles al respecto, pero además, en las reglas 21 , subap. 2.' $b^{\prime}$ y ap. $4 ; 28.7 ; 29.6 ; 32.3 ; 33 .{ }^{\prime} g^{\prime}$, subaps. $x$, xi y xii; y $44.5^{6}$.

Precisamente en el marco norteamericano el instituto ha tenido valor protagónico en causas importantes de la Suprema Corte de Justicia Federal, como las referidas a la problemática antidiscriminatoria ${ }^{7}$, la disputa abortoantiaborto $^{8}$ y la eutanasia ${ }^{9}$ (mercy killing).

En torno al tema, Böhmer advierte que los casos que la Corte Suprema norteamericana selecciona para decidir son paradigmáticos de alguna situación determinada y sientan jurisprudencia sobre el tema para el futuro, agregando que la importancia de tales causas se hace evidente a partir de la gran cantidad de capital social acumulado previamente a la decisión del Tribunal ${ }^{10}$.

Convergentemente, Sola ha precisado que dentro del modelo dialógico de creación de precedentes, el amicus curiae permite la ampliación de participantes en el debate. Así, mientras mayor sea la participación de ideas en el debate constitucional, mayor será la legitimidad del precedente que se establezca y, al mismo tiempo, se cumplirá con el fundamento democrático de que las normas son autoimpuestas y, de allí, obligatorias y legítimas ${ }^{11}$. 


\subsection{Su uso en instancias iusinternacionales}

De la misma manera, la figura ha recibido acogida y, en algunos casos, amplia utilización en el ámbito del derecho internacional de los derechos humanos y otras instancias transnacionales.

En tal sentido pueden computarse los supuestos de la Comisión Interamericana de Derechos Humanos (Comisión IDH), donde tales presentaciones son moneda corriente; la Corte Interamericana de Derechos Humanos (Corte IDH), tanto en asuntos contenciosos como en opiniones consultivas (cfr. artículos 2.3, 41, 47.3 y 67.312); el Tribunal Europeo de Derechos Humanos (artículos 36.2 del Convenio Europeo para la Protección de los Derechos Humanos y de las Libertades Fundamentales, de acuerdo con lo establecido por el artículo $1^{\mathrm{o}}$ del Protocolo $\mathrm{N}^{\circ} 11^{13}$, relativo a la reestructuración del mecanismo de control establecido por el Convenio, norma que establece la "intervención de terceros" ante el Tribunal ${ }^{14}$ ); los órganos de supervisión del sistema africano estatuido por la Carta de los Derechos Humanos y de los Pueblos - Carta de Banjul - , adoptada en 1981 por la Organización de la Unidad Africana y en vigor desde 1986; el Tribunal Penal Internacional para la ex Yugoslavia; los paneles y el Cuerpo de Apelación de la Organización Mundial del Comercio; y hasta el Centro Internacional de Arreglo de Diferencias Relativas a Inversiones (CIADI) ${ }^{15}$.

\subsection{Utilización del instituto por algunos órganos de clausura de la justicia constitucional en Latinoamérica}

Ya en el plano del derecho interno estatal, es preciso destacar enunciativamente algunos casos de utilización del instituto por los respectivos órganos máximos de la jurisdicción constitucional, sea por vía reglamentaria desarrollada por tales tribunales o por materialización legislativa. Nos referimos a la Corte Suprema de Justicia de Argentina, el Tribunal Constitucional del Perú y el Supremo Tribunal Federal de Brasil.

También, y aunque se aparte un tanto de la consigna que anuncia el epígrafe, nos referiremos al tema en México, donde por cierto la figura no resulta desconocida y su instrumentación ha sido reclamada desde algunos sectores de la comunidad jurídica.

\section{A. Argentina}

a) En el orden federal, y sin ley expresa que establezca de modo genérico el instituto, la Corte Suprema de Justicia dictó la Acordada $N^{\circ} 28^{16}$, de 14 
de julio de 2004, en la que autorizó - por mayoría - la intervención de "amigos del tribunal".

Así, con la aprobación de los ministros Petracchi, Boggiano, Maqueda, Zaffaroni y Highton de Nolasco, y las disidencias de los doctores Belluscio, Fayt y Vázquez, el Cuerpo reglamentó la participación de la figura $^{17}$, estipulando los siguientes lineamientos centrales que regirán la actividad de los mismos ${ }^{18}$ :

- Pueden intervenir en calidad de "amigos del tribunal" tanto las personas físicas como las jurídicas que, no siendo parte en el pleito (artículo $1^{\circ}$, párrafo 1 ), ostenten reconocida competencia sobre la cuestión debatida en el mismo (artículo $2^{\circ}$, párrafo 1 );

- La presentación, que no deberá superar las veinte carillas de extensión (artículo $2^{\circ}$, in fine), podrá realizarse dentro de los quince días hábiles del llamado de autos para sentencia (artículo $1^{\circ}$ );

- En ella, el presentante deberá fundamentar su interés en participar de la causa, informar sobre la existencia de algún tipo de relación con las partes del proceso (artículo $2^{\circ}$, párrafo 1) y constituir domicilio en los términos del artículo $40^{\circ}$ del Código Procesal Civil y Comercial de la Nación (artículo $1^{\circ}$, in fine);

- Si el Tribunal estimara pertinente la presentación, ordenará su incorporación al expediente (artículo $3^{\circ}$ );

- La presentación, que puede concretarse en todos los procesos judiciales correspondientes a la competencia originaria o apelada de la Corte en los que se debatan asuntos de trascendencia colectiva o interés general (artículo $1^{\circ}$, párrafo 1), habrá de ser realizada con la única finalidad de expresar una opinión o una sugerencia fundadas sobre el objeto del litigio (artículo $1^{\circ}$, párrafo 2), en defensa de un interés público o de una cuestión institucional relevante (artículo $2^{\circ}$, párrafo 2);

- La opinión o la sugerencia tendrán por objeto ilustrar a la Corte Suprema, la que, aun cuando no quede vinculada por ellas, podrá tomarlas en cuenta en el pronunciamiento que dicte (artículo $5^{\circ}$ ); y

- El "amigo del tribunal" no reviste carácter de parte ni puede asumir ninguno de los derechos procesales que corresponden a estas; al 
tiempo que su actuación no devengará costas ni honorarios judiciales (artículo $4^{\circ}$ ).

Posteriormente, la Corte fue perfilando los alcances dela figura. Asílo hizo, básicamente, en "Juplast S.A. c/ Estado Nacional y A.F.I.P. s/ amparo"19, de 31 de octubre de 2006, donde rechazó numerosas presentaciones de amici por considerar que ellas tenían por objeto "que la causa sea resuelta en un determinado sentido, con la finalidad de que se establezca así un precedente aplicable a otros pleitos de análoga naturaleza -iniciados o por promoverse - en los que los presentantes o sus representados sean parte o tengan un interés de carácter pecuniario comprometido en su resultado. En el indicado supuesto, la existencia de tal interés determina la improcedencia de la intervención como amigos del tribunal de quienes lo tuvieren, pues resulta incompatible con la imparcialidad que debe guiar la actuación de estos" (considerando 3).

Basó primordialmente tal conclusión en que no se satisfacía el recaudo establecido en la Acordada $\mathrm{N}^{\circ}$ 28/2004 en cuanto a que las presentaciones deben ser efectuadas por terceros ajenos a las partes que cuenten con una conocida competencia en la cuestión debatida, "con la única finalidad de expresar una opinión fundada sobre el objeto del litigio" (considerando 2).

Algunos de los lineamientos trazados en "Juplast" nos parecen opinables pues proyectan una imagen restrictiva del instituto, ya que -como advierte Courtis - cuando el Tribunal requiere "imparcialidad" como recaudo a cumplir por los presentantes, puede hacer suponer que estos nunca podrían favorecer a alguna de las posiciones sustentadas por las partes $^{20}$. Añade tal autor que si "este es el sentido de las palabras de los magistrados para definir 'imparcialidad', entonces 'Juplast' representa un retroceso en materia de admisibilidad del amicus. Pues es sumamente plausible que si entendemos a la práctica jurídica como una tarea eminentemente argumentativa, toda razón que se induzca para que el magistrado decida de una u otra manera está revestida de un 'interés'. Si la imparcialidad implica desconocer o - peor aún - exigir que esto no exista, resultaría desconocer una de las características mismas de la práctica argumentativa e interpretativa. Por último, la Acordada en su artículo $2^{\circ}$ exige, por un lado, una reconocida competencia sobre la cuestión debatida en el caso, y, por otro lado, fundar un interés para participar en él. En cuanto a la primera exigencia, creo que esta da buenas razones para presuponer que un amicus goza de un genuino interés de defensa de la cosa 
pública. Y en cuanto a la segunda exigencia, la propia Corte presupone un interés de quien se presenta $y$, con este, la intencionalidad de influir en la decisión final que recae en manos de los magistrados. De allí que aquello que aparece como un requisito para la procedencia del amicus no podría entenderse como un impedimento para el mismo" 21 .

Sea como fuera, las pautas de viabilidad de las presentaciones de los "amigos del tribunal" sentadas en "Juplast" han sido confirmadas posteriormente. Así, en el caso "Loñ, Carolina y otros c/ Gobierno de la Ciudad de Buenos Aires y otros"22, de 13 de noviembre de 2007, la Corte rechazó el pedido de los actores en punto a que se desglosara una articulación formalizada por quienes comparecieron como "amigos del tribunal", ya que consideró que la presentación se ajustaba a lo establecido en la Acordada $\mathrm{N}^{\circ} 28 / 2004$, sin que se advirtiera que hubiese tenido por objeto que la causa fuera resuelta en un determinado sentido, con la finalidad de que se estableciera así un precedente aplicable a otros pleitos de análoga naturaleza - iniciados o por promoverse - en los que los presentantes o sus representados fueran parte o tuvieran un interés de carácter pecuniario comprometido en su resultado.

b) Como apunte marginal, cabe mencionar ya en el marco del derecho público local, que el amicus curiae ha sido expresamente establecido en la ciudad autónoma de Buenos Aires, concretamente, en el artículo $22^{\circ}$ de la Ley $\mathrm{N}^{\circ} 402$ de Procedimientos ante el Tribunal Superior de Justicia de esa ciudad ${ }^{23}$, en el contexto de ejercicio de la acción declarativa de inconstitucionalidad estatuida en el artículo $113^{\circ}$, inciso 2, de su Constitución.

Paralelamente, han hecho lo propio otros tribunales delámbito provincial, tomando como núcleo referencial a la citada Acordada $N^{\circ}$ 28/2004 de la CorteSuprema de Justicia Nacional. Así, ejemplificativamente, el Superior Tribunal de Justicia de Río Negro, que lo hizo en la Sentencia N ${ }^{\circ} 41 / 04$ (Secretaría de Causas Originarias $\mathrm{N}^{\circ} 4$ ), de 2 de septiembre de 2004, en Expediente $\mathrm{N}^{\circ}$ 19.565/04, “Odarda, María Magdalena (amicus curiae) s/ Presentación", quedando luego la figura implementada normativamente por medio de la Ley Provincial $N^{\circ} 4.18524$; y la Suprema Corte de Justicia de Mendoza, cuya Sala Primera admitió la figura por vez primera en la causa N 83.665: “Curel, Gastón Oscar y otros en J’ 30.554/114.678, Mancilla Cuello, Enrique Ariel y otros c/ Municipalidad de la ciudad de Mendoza p/ Acción de Amparo s/ Inc.", resuelta el 3 de febrero de $2006^{25}$. 


\section{B. Perú}

El artículo 13.A del Reglamento Normativo del Tribunal Constitucional (aprobado mediante Resolución Administrativa Nº 095-2004-P-TC) establece: "El Pleno o las Salas pueden solicitar información de los amicus curiae (amici curiarum), si fuera el caso, a fin de esclarecer aspectos especializados que puedan surgir del estudio de los actuados".

Por su parte, el artículo $34^{\circ}$ de dicho Reglamento, determina: "Luego de instalada la audiencia, el presidente dispone que el relator dé cuenta, en forma sucesiva, de las causas programadas, precisando el número de expediente, las partes que intervienen y la naturaleza de la pretensión. El presidente concede el uso de la palabra, hasta por cinco minutos al demandante y por igual tiempo al demandado, quienes se ubicarán a la izquierda y la derecha, respectivamente, frente a los magistrados. A continuación, el presidente concede el uso de la palabra a los abogados del demandante y del demandado, por el mismo tiempo, los cuales se ubicarán en igual forma que sus defendidos. Está permitida la réplica y dúplica a los abogados por el tiempo que determine el presidente. Por último, cuando corresponda, se recibirá la participación del amicus curiae".

Para finalizar esta breve referencia, y ciñéndonos ahora a la jurisprudencia del Tribunal, pueden relevarse ejemplificativamente los siguientes casos de operativización práctica de la figura: Expedientes 020-2005-PI/TC y 0212005-PI/TC (acumulados, Caso Hoja de Coca), sentencia de 27 de septiembre de 2005 (Pleno Jurisdiccional); y Expediente N 3.081-2007-PA/TC, Lima, "R.J.S.A. viuda de R.", recurso de agravio constitucional en proceso de amparo en torno a la problemática de la salud mental, resuelto el 9 de noviembre de 2007 (Sala Segunda).

\section{Brasil}

El Supremo Tribunal Federal (STF), aun antes de la enmienda reglamentaria $\mathrm{N}^{\circ} 15 / 04$ que modificó el $\S 3^{\circ}$ del artículo $131^{\circ}$ del Reglamento Interno del $\mathrm{STF}$, para disciplinar la intervención de terceros en procesos de control concentrado de constitucionalidad, ya había decidido algunos procesos de ADIn (Ação Direta de Inconstitucionalidade) viabilizando la participación de terceros; por ejemplo, como señala Da Cunha Ferraz, sobre el particular puede verse el relato y el voto del Ministro Celso de Mello en la ADIn 2321-MC/DF, generando una construcción jurisprudencial sobre la figura del amicus curiae que entrañó un verdadero leading $\operatorname{case}^{26}$. 
Más aún, se ha sostenido que de la interpretación del $\S 2^{\circ}$ del artículo $7^{\circ}$ de la Ley $\mathrm{N}^{\circ} 9.868 / 99$, surge que además de los órganos y entidades formalmente legitimados para articular la ADIn, también lo están cualesquiera otros entes dotados de significativa representatividad, llegándose a aseverar que el STF permitió la participación de amici curiarum ya antes del dictado de tal ley, por ejemplo en la ADIn 748-4/RS (de 1994), receptando los memoriales de amici al visualizar a estos como colaboradores informales del Tribunal en las acciones directas de inconstitucionalidad, sin integrar la relación procesal ${ }^{27}$.

\section{México}

Si bien la situación es diferente de las analizadas hasta ahora, vale la pena un repaso del caso mexicano, donde el instituto del amicus curiae no es desconocido y desde algunos sectores se reclama su instauración.

a) Entre los años 2003 y 2004 la Suprema Corte de Justicia llevó adelante la Consulta Nacional para una Reforma Integral y Coherente del Sistema de Impartición de Justicia en el Estado Mexicano, cuyos resultados quedaron plasmados en el denominado Libro Blanco de la Reforma Judicial ${ }^{28}$.

Dicho documento fue redactado por los doctores José Antonio Caballero Juárez y Sergio López Ayllón y el maestro Alfonso Oñate Laborde; a quienes el Comité Organizador de la Consulta Nacional (compuesto por los ministros del Máximo Tribunal Federal, Mariano Azuela Güitrón, José Ramón Cossío Díaz y José de Jesús Gudiño Pelayo), encomendó tal tarea.

Los redactores del Libro Blanco, al interpretar los resultados de la Consulta Nacional ${ }^{29}$, identificaron tres ejes temáticos esenciales: la reforma del amparo, el fortalecimiento de los poderes judiciales de las entidades federativas y la reforma de la justicia penal ${ }^{30}$.

Asimismo, relevaron la existencia de otras propuestas expuestas durante la Consulta que también identificaron como "prioritarias". Justamente, entre estas, se contempla expresamente (en la denominada "Acción 22") la introducción del amicus curiae en procesos constitucionales ${ }^{31}$.

Sobre el punto, el resultado de la Consulta ha sido interpretado y sintetizado por los indicados autores de la siguiente manera: "Las funciones de un tribunal constitucional trascienden el interés de las partes en conflicto. Por ello, para lograr un mayor acceso a la justicia y promover una 
mejor y más amplia participación social en la defensa de los derechos fundamentales y las controversias políticas, se debe introducir la figura del amicus curiae en algunos mecanismos procesales existentes (e.g. controversias constitucionales, acciones de inconstitucionalidad, contradicciones de tesis e, incluso en ciertas hipótesis, el propio amparo). Existen diversas maneras de lograr este objetivo, discutidas en la sección correspondiente de este Libro Blanco, y que incluyen desde una reforma constitucional hasta modificaciones legislativas. Sin embargo, su implementación también puede lograrse en el corto plazo mediante una decisión de la Suprema Corte de Justicia de la Nación en esta dirección. En cualquier hipótesis es necesario subrayar que este mecanismo supone el ejercicio de una facultad discrecional del tribunal quien debe determinar en cada caso la manera en que el amicus curiae contribuye a informar su decisión" 32 .

b) Para culminar este acercamiento, cabe recordar que en ocasiones el Gobierno de México ha comparecido ante tribunales extranjeros en calidad de amicus curiae.

Solo ejemplificativamente, a continuación evocaremos dos antecedentes al respecto:

En primer lugar, el caso "Estados Unidos de América vs. Humberto Álvarez-Machain" 33 , resuelto por la Suprema Corte de Justicia de EE.UU. el 15 de junio de 1992, en una causa en la que Álvarez-Machain había sido acusado de secuestrar, torturar y matar en 1985 a un agente de la Drug Enforcement Administration (DEA) y en la que en 1990 el inculpado fue sustraído de su consultorio médico en Guadalajara (México) y trasladado en avión a El Paso (Texas), sitio donde fue arrestado por oficiales de la DEA. En su memorial amicus curiae el gobierno mexicano solicitaba que aquella Suprema Corte juzgara que la sentencia del Tribunal de Apelación (confirmatoria de la del Tribunal de Distrito, que ordenaba que Álvarez-Machain fuera regresado a México) era consistente con el derecho internacional y, por ende, que el acusado debía ser restituido a territorio mexicano. Asimismo, indicó que el secuestro de aquel en territorio mexicano por agentes de EE.UU. para ser juzgado en ese país, era incompatible con los principios establecidos por el derecho internacional y con las posiciones adoptadas expresamente por EE.UU. en tratados bilaterales y multilaterales sobre mutua asistencia jurídica en materias penales y cooperación para combatir el tráfico de drogas que estaban vigentes entre México y EE.UU. al tiempo del citado secuestro. 
No obstante, el máximo Tribunal estadounidense dejó sin efecto el fallo del Tribunal de Apelación y señaló (entre diversas consideraciones) que del Tratado de Extradición entre EE.UU. y México no podía deducirse la existencia de una cláusula prohibitiva de los secuestros internacionales; que el secuestro de Álvarez-Machain (aun cuando hubiese sido violento) no había violado aquel tratado, y que el hecho de que este hubiese sido secuestrado no impedía su enjuiciamiento por un tribunal de los EE.UU. ante la violación al derecho penal de este país. Terminó decidiendo que el caso se sujetaría en lo sucesivo a lo dispuesto en su resolución. Finalmente, en fecha 14 de diciembre de 1992, Álvarez-Machain fue liberado por el Tribunal del Distrito Central de California regresando entonces a México.

Más recientemente, el Gobierno mexicano lo hizo en una causa en la que participaron además como amici otros doce países latinoamericanos y cuarenta y siete naciones de la Unión Europea y del Consejo de Europa, ante la Suprema Corte de Justicia de EE.UU., a favor del mexicano José Ernesto Medellín Rojas, sentenciado a muerte en el Estado de Texas. Fundamentalmente la base de la defensa, apuntalada argumentalmente por las presentaciones de los asistentes oficiosos, se centraba en el pronunciamiento de la Corte Internacional de Justicia (CIJ) en el caso "Avena", por el cual ordenó a EE.UU. revisar y reconsiderar las condenas de cincuentiún mexicanos sentenciados a muerte -incluido el Sr. Medellín - a la luz de las violaciones de su derecho a la notificación y asistencia consular; así como en el Memorando del ex Presidente Bush, ordenando a las Cortes de los Estados de ese país dar cumplimiento al fallo del tribunal internacional. La Suprema Corte Federal, por mayoría, rechazó el writ of certiorari el 25 de marzo de 2008 argumentando que ni del Estatuto de la CIJ, ni de la propia Carta de la Organización de las Naciones Unidas surgía la obligación para EE.UU. de cumplir el fallo "Avena" a través de sus tribunales, además de considerar que el (ex) Presidente Bush se excedió en sus facultades constitucionales al pretender que las cortes estatales dieran cumplimiento a tal decisorio ${ }^{34}$.

\section{LINEAMIENTOS GENERALES DEL AMICUS CURIAE}

\subsection{Mutación de su rol}

En un principio, la participación del "amigo del tribunal" estaba enderezada principalmentea ayudarneutralmentealórganojurisdiccionaly proporcionarle información en torno a cuestiones esencialmente jurídicas respecto de las que 
aquel pudiere albergar dudas o estar equivocado en el criterio asumido hasta entonces sobreel particular, acercándolefallos jurisprudenciales o antecedentes doctrinarios útiles para dirimir casos con cierto grado de complejidad.

Sin embargo, hoy ha abandonado su carácter otrora imparcial ${ }^{35}$, para convertirse en una suerte de interviniente interesado y comprometido, que argumenta jurídicamente para obtener un pronunciamiento favorable a la posición que auspicia ${ }^{36}$.

Incluso Cueto Rúa ha llegado a afirmar que en la actualidad no se le pide neutralidad; sí se espera, en cambio, una inteligente contribución sobre los problemas planteados por el caso y su repercusión respecto de terceros y demás integrantes de la comunidad, aun a sabiendas que el 'amicus' es el 'amicus' del actor o el demandado ${ }^{37}$ (énfasis añadido).

\subsection{Su importancia cuando deben resolverse jurisdiccionalmente cuestiones jurídica y axiológicamente dilemáticas}

Los amici pueden constituir herramientas válidas para funcionar en la resolución de cuestiones controversiales y que presenten significativos dilemas éticos o de otra índole, por ejemplo, de análisis constitucional de una normativa de importancia o sensibilidad públicas en las que la decisión por recaer sea susceptible de marcar una guía jurisprudencial para otros casos pendientes $^{38}$.

Es decir, asuntos en los que esté en juego un interés público relevante cuya dilucidación judicial ostente una fuerte proyección o trascendencia colectivas; en otras palabras, temáticas que excedan el mero interés de las partes. Solo por citar algunas hipótesis, la autorización para proceder a la interrupción del embarazo por anencefalia, el debate sobre la viabilidad de la eutanasia o la discusión en torno a la desincriminación del aborto o de la tenencia de droga para consumo personal.

Utilizando mutatis mutandi las terminologías de la teoría jurídica empleadas (disputadamente) por Hart ${ }^{39}$ o Dworkin ${ }^{40}$, el instituto que analizamos podría suponer un útil recurso para operar en los casos difíciles, es decir - en una simplificación extrema-, aquellos en los que -inter alia - exista incerteza, sea porque converjan varias normas que determinan sentencias distintas (en tanto tales previsiones normativas son contradictorias), sea porque no exista norma exactamente aplicable. $\mathrm{O}$, profundizando aún más en el acercamiento referencial, el instituto en cuestión podría ser de provecho quizá también en 
lo que Atienza considera como casos trágicos, esto es, los que constituyen un tipo de casos difíciles que se presentan como verdaderos dilemas, donde cualesquiera sean las respuestas que se seleccionen, no cabría encontrar ninguna solución jurídica que no sacrifique algún elemento esencial de un valor considerado como fundamental desde el punto de vista jurídico y/o moral $^{41}$.

Así visualizada, la institución que examinamos - como pudimos apreciar, de extendido empleo en diversos ámbitos del derecho comparado - es una herramienta idónea para propiciar lo que Morello denomina el proceso justo constitucional desde la perspectiva del justiciable, o sea, de quien reclama de la jurisdicción la tutela efectiva ${ }^{42}$.

\section{OTRO ESPACIO TRASCENDENTE EN EL QUE EL APORTE DE AMICI SE HACE PARTICULARMENTE PERCEPTIBLE}

\subsection{Contexto}

Complementariamente a lo manifestado en el apartado anterior, el instituto que abordamos puede aún reportar una utilidad adicional en el ámbito jurídico interno (también en el internacional); conclusión que aflora a poco de reparar en ciertos rasgos que actualmente tipifican a este último, tales como el alto grado de desarrollo adquirido por el derecho internacional de los derechos humanos, la envergadura de los instrumentos internacionales en dicha materia frente al derecho doméstico y la fuerza que cobran los informes, las recomendaciones, las decisiones y las opiniones consultivas de los órganos protectorios en las instancias internacionales (por ejemplo, la Comisión y la Corte IDH), a cuyos repertorios de precedentes (en el caso de la Comisión) y jurisprudencia (en el de la Corte) deberían adaptarse las soluciones jurisdiccionales dispensadas en los escenarios judiciales locales.

En un marco con características de tal magnitud, los amici pueden cumplir un papel significativo al proporcionar a los magistrados elementos de juicio actualizados en materia de derechos humanos, relativos a la interpretación y la aplicación de los tratados internacionales sobre tal materia, por ejemplo, por parte de los aludidos órganos del sistema protectorio interamericano.

Conviene entonces pulsar el botón de alerta en torno a este asunto, ya que en la hora actual los puntos de contacto entre el derecho internacional de los derechos humanos y el derecho interno se multiplican, acentuándose la exigencia de lograr una pacífica articulación de tales fuentes mediante su 
retroalimentación y complementariedad a favor de la solidificación del sistema general de derechos, y pugnar por el cumplimiento por parte del Estado de los compromisos internacionalmente asumidos en la materia y por evitar que este incurra en responsabilidad internacional; tareas en cuya realización la magistratura judicial asume un rol protagónico.

\subsection{La intervinculación de los controles de constitucionalidad y convencionalidad}

No podemos dejar de señalar que la Corte IDH ha emitido en fecha relativamente reciente una sentencia en la que transmite un claro mensaje a los jueces internos de los Estados Parte de la Convención Americana sobre Derechos Humanos (CADH). Se trata del "Caso Almonacid Arellano", en el que se ha pronunciado en los siguientes términos: "La Corte es consciente que los jueces y tribunales internos están sujetos al imperio de la ley y, por ello, están obligados a aplicar las disposiciones vigentes en el ordenamiento jurídico. Pero cuando un Estado ha ratificado un tratado internacional como la Convención Americana, sus jueces, como parte del aparato del Estado, también están sometidos a ella, lo que les obliga a velar porque los efectos de las disposiciones de la Convención no se vean mermados por la aplicación de leyes contrarias a su objeto y fin, y que desde un inicio carecen de efectos jurídicos. En otras palabras, el Poder Judicial debe ejercer una especie de 'control de convencionalidad' entre las normas jurídicas internas que aplican en los casos concretos y la Convención Americana sobre Derechos Humanos. En esta tarea, el Poder Judicial debe tener en cuenta no solamente el tratado, sino también la interpretación que del mismo ha hecho la Corte Interamericana, intérprete última de la Convención Americana" (remarcado añadido) ${ }^{43}$.

El Tribunal Interamericano ha ido aún más allá, estableciendo que tal control de convencionalidad por la magistratura local debe ejercerse incluso de oficio. En efecto, en el caso de Trabajadores Cesados del Congreso", puso de manifiesto que "[...] los órganos del Poder Judicial deben ejercer no solo un control de constitucionalidad, sino también 'de convencionalidad' ex officio entre las normas internas y la Convención Americana, evidentemente en el marco de sus respectivas competencias y de las regulaciones procesales correspondientes $[\ldots]^{\prime \prime 4}$.

Dicho de otro modo, la Corte IDH impone a los poderes judiciales de los Estados la obligación de concretar el control de convencionalidad de las normas jurídicas internas que aplican en los casos concretos vis a vis la $\mathrm{CADH}$, tomando en consideración al efecto no sólo la literalidad de dicho pacto sino 
la lectura que del mismo ha realizado el Tribunal Interamericano que, como se sabe, es el intérprete último de aquél. Realza, así, la operatividad de la pauta de interpretación conforme a la CADH como estándar hermenéutico a respetar y resguardar por parte de los órganos jurisdiccionales vernáculos (incluso de oficio), dinámica en la que subyace la idea de retroalimentación entre el control de constitucionalidad y el control de convencionalidad.

En "Mazzeo, Julio Lilo y otros s/ recurso de casación e inconstitucionalidad" 45 , de 13 de julio de 2007, la Corte de Justicia argentina - por mayoría ${ }^{46}$ - aportó un relevante enfoque institucional en torno a la invalidez constitucional de la atribución presidencial de emitir indultos que beneficien a sujetos acusados de cometer delitos de lesa humanidad (ver, por ejemplo, el considerando 31 de la moción mayoritaria). Para conformar tal matriz argumental ha receptado expresamente la pauta adoptada por la Corte IDH en el párrafo 124 de la sentencia recaída en "Almonacid Arellano", siendo al efecto particularmente relevante el considerando 21 de la posición triunfante de nuestro máximo tribunal en punto al deber del poder judicial local de realizar el control de convencionalidad, lo que - añadimos por nuestra parte - significa discernir si una norma interna es o no "convencional".

En definitiva, y como el tribunal interamericano dejó en claro en el "Caso Boyce y otros", ello significa que no alcanza con limitarse a evaluar si una norma es inconstitucional, sino que la cuestión debe girar en torno a si la misma también es "convencional", o sea, debe además el órgano jurisdiccional en cuestión decidir si ella restringe o viola los derechos reconocidos en la $\mathrm{CADH}^{47}$.

\subsection{Una potencialmente valiosa contribución argumental en los ámbitos interno e internacional}

Es de subrayar que si la mayoría de los Estados latinoamericanos ha aceptado la jurisdicción contenciosa de la Corte IDH, si además ante esta existe la posibilidad de comparecer en calidad de amicus curiae y si llegar con un caso ante la misma supone el agotamiento previo de los recursos internos del Estado demandado, requisito concedido en interés del propio Estado, no resulta razonable prohibir - como expresan Abregú y Courtis $^{48}$ - a instituciones o grupos interesados presentarse en carácter de amici ante los tribunales locales (oportunidad frente a la que el Estado tiene posibilidades de remediar la alegada violación) y conceder esa posibilidad después, cuando el Estado ya ha sido demandado ante la Corte por la imputación de los mismos hechos. Es que, siendo la instancia interamericana coadyuvante o complementaria de la que prodiga el derecho interno, es recomendable ofrecer a los interesados en 
articular opiniones fundadas sobre el tema en cuestión la misma posibilidad de participación procesal en sede local que la que tienen en el ámbito internacional, adelantando ante los tribunales domésticos los argumentos que eventualmente serán considerados por la Corte con asiento en Costa Rica.

Precisamente esta ha reiterado que los amici son presentaciones de terceros ajenos a la disputa, que le aportan argumentos $u$ opiniones que pueden servir como elementos de juicio relativos a aspectos de derecho que se ventilan ante la misma ${ }^{49}$.

Al respecto, conviene evocar que el Reglamento de la Corte IDH reformado parcialmente en fecha reciente (innovación en vigor desde el 24 de marzo de 2009), en su artículo 2.3. define el término amicus curiae de la siguiente manera: "la persona ajena al litigio y al proceso que presenta a la Corte razonamientos en torno a los hechos contenidos en la demanda o formula consideraciones jurídicas sobre la materia del proceso, a través de un documento o de un alegato en audiencia".

Como puede leerse en la exposición de motivos de las modificaciones reglamentarias introducidas al Reglamento de la Corte IDH, varias de las observaciones remitidas a esta durante la etapa preparatoria de las reformas, manifestaban la necesidad de reglamentar la presentación de escritos de los amici curiarum, razón por la cual en el artículo $41^{\circ}$ se decidió establecer que "el escrito de quien desee actuar como amicus curiae podrá ser presentado al Tribunal, junto con sus anexos, en cualquier momento del proceso contencioso pero dentro de los quince días posteriores a la celebración de la audiencia pública. En los casos en que no se celebra audiencia pública, deberán ser remitidos dentro de los quince días posteriores a la Resolución correspondiente en la que se otorga plazo para la remisión de alegatos finales y prueba documental. El escrito del amicus curiae, junto con sus anexos, se pondrá de inmediato en conocimiento de las partes para su información, previa consulta con la Presidencia" ${ }^{50}$.

Por último, y previo a pasar a las observaciones de cierre de este trabajo, no puede perderse de vista que la Corte IDH ha resaltado que "los asuntos que son de su conocimiento poseen una trascendencia o interés general que justifica la mayor deliberación posible de argumentos públicamente ponderados, razón por la cual los amici curiae tienen un importante valor para el fortalecimiento del sistema interamericano de protección de los derechos humanos, a través de reflexiones aportadas por miembros de la sociedad, que contribuyen al debate y amplían los elementos de juicio con que cuenta la Corte" 51 . 


\section{OBSERVACIONES DE CIERRE}

Consideramos que la intervención de amicus curiae puede coadyuvar a un mejoramiento de la actividad jurisdiccional en asuntos complejos o de interés social, contribuyendo incluso a diluir los aspectos antimayoritarios negativos que algunos autores predican del control judicial de constitucionalidad $^{52}$, además de que no es un argumento menor el que trae Trionfetti en punto a que "la insularidad de la tarea judicial, la concepción del juez como una suerte de demiurgo que construye en soledad su decisión [...], solo constituyen anteojeras epistemológicas que obturan cualquier debate y son oclusivos de la posibilidad de enriquecerlo" 53 .

Visionariamente, al realizar una defensa condicionada de la judicial review y en el marco de análisis de las reformas para aportar al "control democrático" de esta, Carrió postulaba introducir la institución del amicus curiae, ya que el debate judicial adquiriría con ella una apertura y una amplitud de integración que no tenían en medida suficiente los procedimientos contradictorios, añadiendo que el debate se volvería más democrático, en un sentido interesante (y relevante en este campo) de esa palabra ${ }^{54}$.

En esa línea, y como lo puntualizara nuestra Corte Suprema de Justicia, la institución que abordamos es un provechoso instrumento destinado, entre otros objetivos, a permitir la participación ciudadana en la administración de justicia, en los casos en que se ventilen asuntos de trascendencia institucional o que resulten de interés público, siempre que los presentantes cuenten con una reconocida competencia sobre la materia debatida ${ }^{55}$.

En esa línea analítica, cabe recordar - con Nino - que la figura presenta una destacada raíz democrática y su intervención entraña una herramienta para hacer más laxos los criterios de participación en el proceso judicial en el marco del activismo judicial, actitud esta que se muestra fructífera para promover y ampliar el proceso democrático, abriendo nuevos canales de participación, sobre todo, de los grupos con menos posibilidades de injerencia real en ese proceso $^{56}$.

A su tiempo la Corte IDH se ha ocupado de subrayar que los amici tienen un importante valor para el fortalecimiento del sistema interamericano de protección de los derechos humanos, contribuyen al debate y amplían los elementos de juicio con que el tribunal cuenta para resolver los asuntos de su conocimiento, que poseen una trascendencia o interés generales ${ }^{57}$. 
De ello se desprende que la figura puede proveer un valioso caudal argumental no solo a los tribunales locales sino también a los órganos jurisdiccionales internacionales, lo que representa una muestra más del crecimiento de los espacios de convergencia interactiva del derecho constitucional, el procesal constitucional y el internacional de los derechos humanos.

En síntesis, estimamos que el amicus curiae es un instrumento plausible y digno de ser explorado para tonificar el debate judicial - ampliando los márgenes de deliberación en cuestiones de trascendencia social por medio de argumentos públicamente analizados - , aportar a la defensa y la realización de los derechos humanos y contribuir a la elaboración de sentencias razonables y generadoras de un grado sustentable de consenso en la comunidad.

1 Se ha explicado que en la actualidad casi un tercio de la población mundial habita en regiones cuyo derecho ha tenido influencia del Common Law, ya que la expansión colonial de Gran Bretaña se encargó de extenderlo a Norteamérica, la India, Australia, Nueva Zelanda, y a grandes sectores del África y del sudeste asiático (cfr. Zweigert, Konrad y Köтz, Heinz. An Introduction to Comparative Law. Segunda Edición. Oxford University Press. Gran Bretaña, 1992, p. 227; cit. por Morineau, Marta. Una introducción al 'Common Law'. Instituto de Investigaciones Jurídicas. Universidad Nacional Autónoma de México. México, D.F., 2001, pp. 46-47).

2 Zagrebelsky, Gustavo. El Derecho Dúctil, Ley, Derechos, Justicia. Trad. de Marina Gascón. Tercera Edición. Madrid: Trotta, 1999, p. 147.

3 Cfr. Trionfetti, Víctor. «El Enriquecimiento del Debate Judicial a través de la Figura del Amicus Curiae». La Ley. Buenos Aires, 2003-F-71.

4 Cfr. Cueto Rúa, Julio C. «Acerca del Amicus Curiae». La Ley. Buenos Aires, 1988-D-721.

5 Cfr. Umbricht, Georg C. "An 'Amicus Curiae Brief' on Amicus Curiae Briefs at the WTO» Journal of International Economic Law, p. 780, nota 32 a pie de página.

6 El texto de las «Rules» puede consultarse en www.supremecourtus.gov/ctrules/2007rulesofthecourt.pdf.

7 V.gr. «Regents of the University of California vs. Bakke» (438 U.S. 265 [1978]).

8 «Webster vs. Reproductive Health Services» (492 U.S. 490 [1989]).

9 Así, en ocasión del debate sobre la constitucionalidad de las leyes de los Estados de Washington y Nueva York que prohibían a los médicos ayudar a morir a los pacientes que así lo solicitaban, es posible verificar por ejemplo la presentación de un memorial de amicus por seis filósofos morales y políticos de indiscutidos predicamento científico y estatura intelectual: Ronald Dworkin, Thomas Nagel, Robert Nozick, John Rawls, Thomas Scanlon y Judith Jarvis Thomson.

También, y sin abandonar el marco meramente referencial, se presentaron como amici 72 premios Nobel (además de diversas academias de ciencias estatales y otras organizaciones científicas) en el caso "Edwards vs. Aguillard" ante la Suprema Corte de Justicia de EE.UU. (482 U.S. 578 [1987]), fallado el 19 de junio de 1987. Aquí finalmente se confirmó por mayoría (7 a 2) la declaración de inconstitucionalidad de una ley del Estado de Louisiana ("Balanced Treatment for Creation-Science and Evolution-Science in Public School Instruction Act") que proscribía enseñar en las escuelas públicas la teoría de la evolución salvo que fuese acompañada de la enseñanza del creacionismo bíblico. Entre otros argumentos, los amici señalaron que "la enseñanza de ideas religiosas etiquetan incorrectamente cómo la ciencia es perjudicial para la educación científica: establece un falso conflicto entre la ciencia y la religión, engaña a nuestra juventud sobre la naturaleza de la investigación científica y, por tanto, compromete nuestra capacidad de responder a los problemas de un mundo cada vez más tecnológico" ("Teaching religious ideas mislabeled as science is detrimental to scientific education: It sets up a false conflict between science and religion, misleads our youth about the nature of scientific inquiry, and thereby compromises our ability to respond to the problems of an increasingly technological world"). La anticonstitucionalidad se basó en la violación de la cláusula de establecimiento contenida en la Primera Enmienda de la Constitución estadounidense. En su parte pertinente, aquélla dispone que el Congreso no dictará ley alguna por la que adopte una religión como oficial del Estado o se prohíba practicarla libremente ("Congress shall make no law respecting an establishment of religion, or prohibiting the free exercise thereof"). 
${ }^{10}$ Böhmer, Martín. «Introducción a los Amici Curiae». Perspectivas Bioéticas en las Américas. N 4 . Segundo semestre, 1997, pp. 101-102.

11 Sola, Juan V. «El recurso extraordinario y el debate constitucional». En: el 'Número especial: Recurso extraordinario federal'. Jurisprudencia Argentina. 26 de marzo de 2003. Buenos Aires, p. 95.

12 Cfr. el texto del Reglamento aprobado por la Corte en su XLIX Período Ordinario de Sesiones celebrado del 16 al 25 de noviembre de 2000 y reformado parcialmente en el LXXXII Período Ordinario de Sesiones del Tribunal, celebrado del 19 al 31 de enero de 2009.

13 Protocolo que entró en vigencia el 1 de noviembre de 1998.

14 El Protocolo $N^{\circ} 14$ a dicho Convenio (que propone modificar el sistema de control vigente), por medio de su artículo 13 proyecta adicionar un nuevo parágrafo al final del mencionado artículo $36^{\circ}$ del Convenio, disponiendo: "3. In all cases before a Chamber or the Grand Chamber, the Council of Europe Commissioner for Human Rights may submit written comments and take part in hearings".

15 Para ampliar sobre el tema en el derecho comparado, ver Bazán, Víctor, por ejemplo, en «El amicus curiae en el derecho comparado y su instrumentación reglamentaria por la Corte Suprema de Justicia argentina». Anuario Iberoamericano de Justicia Constitucional. $N^{\circ}$ 10. 2006. Madrid: Centro de Estudios Políticos y Constitucionales, 2006, pp. 15-50; y «El amicus curiae y la utilidad de su intervención procesal: una visión de derecho comparado, con particular énfasis en el derecho argentino». Estudios Constitucionales. Revista del Centro de Estudios Constitucionales. Universidad de Talca. Santiago, 2003, pp. 675-714.

16 Un análisis específico de la reglamentación citada en el texto puede consultarse en Bazán, Víctor. «La Corte Suprema de Justicia de la Nación y un importante respaldo institucional a la figura del amicus curiae». Jurisprudencia Argentina. Suplemento de Jurisprudencia de la Corte Suprema de Justicia de la Nación. Buenos Aires: LexisNexis, 29 de setiembre de 2004, pp. 5-16.

17 El Acuerdo y el Reglamento - en la visión de la mayoría - utilizan exclusivamente las expresiones "amigo/s del Tribunal" y no las de "amicus curiaelamici curiarum" o "asistente/s oficioso/s"; en cambio, la posición minoritaria sí contiene alguna alusión a estas últimas.

${ }^{18}$ Los números de artículos que se mencionarán en la reseña que sigue en el texto principal corresponden al "Reglamento sobre Intervención de Amigos del Tribunal", el que, como dijimos, figura como anexo del acuerdo en cuestión.

19 Fallos, 329:4590. El decisorio fue firmado por los doctores Petracchi, Highton de Nolasco, Maqueda, Lorenzetti y Argibay.

20 Courtis, Christian. «Sobre el amicus curiae». En: Gargarella, Roberto (coord.). Teoría y Crítica del Derecho Constitucional. T. I. Buenos Aires: Abeledo-Perrot, 2008, p. 344, nota 44 a pie de página.

${ }^{21}$ Ibídem.

${ }^{22}$ Causa "L.470. XLII". Resolución firmada por los ministros Lorenzetti, Highton de Nolasco, Petracchi, Maqueda y Zaffaroni.

${ }^{23}$ Sancionada el 8 de junio de 2000, y promulgada y publicada, respectivamente, el 6 y el 17 de julio del mismo año.

${ }^{24}$ Sancionada el 19 de abril de 2007, y promulgada y publicada, respectivamente, el 7 y el 21 de mayo del mismo año.

${ }_{25}$ Para una breve noticia de este último fallo, puede compulsarse Bazán, Víctor, «El amicus curiae y su debut en la jurisprudencia de la Sala Primera de la Suprema Corte de Justicia de Mendoza». La Ley Gran Cuyo. Año 11. $\mathrm{N}^{\circ}$ 6. Buenos Aires, pp. 736-738.

${ }^{26}$ Da Cunha Ferraz, Anna Candida. "O amicus curiae e a democratização e a legitimação da jurisdição constitucional concentrada». Revista Mestrado em Direito. Direitos Humanos Fundamentais. Año 8. N 1. 2008. São Paulo: Unifieo, pp. 65 y ss.

27 Amaury Maia Nunes, Jorge. «A participação do amicus curiae no procedimento da Argüição de Descumprimento de Preceito Fundamental (ADPF)». Direito Público. Año V. N 20, marzo-abril de 2008. Brasília: Instituto Brasiliense de Direito Público, pp. 54-55.

28 Suprema Corte de Justicia de la Nación. Libro Blanco de la Reforma Judicial. Una agenda para la justicia en México. Primera Edición. México, D.F., agosto, 2006.

${ }^{29}$ Interpretación que la Suprema Corte de Justicia se encarga de aclarar que es de exclusiva responsabilidad de los autores de los resultados de la Consulta Nacional, y no representa la opinión institucional del Comité Organizador de la misma (ibídem p. 4).

30 Ibídem, p. 389.

31 Ibídem, p. 403.

32 Ibídem.

33504 U.S. 655 (1992).

34 Ver para ampliar www.ime.gob.mx/noticias/boletines_lazos/2007/655.htm. 
35 Como gráficamente se ha afirmado, "what was once a gesture of friendship has become a deliberate act of advocacy". (Krislov, Samuel. «The Amicus Curiae Brief: from Friendship to Advocacy», Yale Law Journal. T. 72. 1963, p. 694).

36 Ibídem.

37 Cueto Rúa, Julio C., Ob. Cit., p. 723.

38 En torno a la cuestión, ver entre otros trabajos de Bazán, Víctor. «Amicus curiae, transparencia del debate judicial y debido proceso». Anuario de Derecho Constitucional Latinoamericano 2004. T. II. Montevideo: Fundación Konrad Adenauer, 2004, pp. 251-280.

39 Hart, Herbert. The concept of Law. Oxford: Clarendon Press, 1961. Es ya un clásico la versión traducida por Genaró Carrió. El concepto de derecho. Buenos Aires: Abeledo-Perrot, 1963.

40 Ver Dworkin, Ronald. Los derechos en serio. Trad. de Marta Guastavino. Cuarta reimpresión. Ariel, Barcelona, 1999, pp. 146/208, y el interesante prólogo de Calsamiglia, Albert, que, bajo el título «Ensayo sobre Dworkin», presenta la obra (vid. concretamente p. 13).

41 Atienza, Manuel. «Los límites de la interpretación constitucional. De nuevo sobre los casos trágicos». En: Vázquez, Rodolfo (comp.). Interpretación jurídica y decisión judicial. Tercera Reimpresión. México, D.F., Fontamara, 2003, pp. 194, 195, 196, 198 y otras.

42 El eminente jurista Augusto M. Morello, cuya reciente y lamentable desaparición física (21 de abril de 2009) nos ha provocado profundo dolor por todo lo que su figura representa para el derecho argentino, en la formulación de sus apreciaciones - a las que escuetamente aludimos en nuestro texto- se basa en doctrina española e italiana (vid. «Del debido proceso y la defensa en juicio al proceso justo constitucional». La Ley. T. 2003-D. Buenos Aires, pp. 1163-1168, en esp. - respecto de la consideración aquí volcada - pp. 1164-1165).

43 Corte IDH, "Caso Almonacid Arellano y otros vs. Chile", Sentencia sobre Excepciones Preliminares, Fondo, Reparaciones y Costas, 26 de septiembre de 2006, Serie C, N 154, párr. 124. También lo ha expresado, v.gr., en el "Caso La Cantuta vs. Perú", Sentencia sobre Fondo, Reparaciones y Costas, 29 de noviembre de 2006, Serie C, $\mathrm{N}^{\circ} 162$, párrafo 173.

44 Corte IDH, "Caso Trabajadores Cesados del Congreso (Aguado Alfaro y otros) vs. Perú", Sentencia sobre Excepciones Preliminares, Fondo, Reparaciones y Costas, 24 de noviembre de 2006, Serie C, N 158, párrafo 128.

45 Fallos, 330:3248.

${ }^{46}$ Los alineamientos fueron: por la mayoría, los doctores Lorenzetti, Highton de Nolasco, Maqueda y Zaffaroni; en disidencia se expidió el ministro Fayt y en disidencia parcial lo hizo la doctora Argibay.

47 Corte IDH, "Caso Boyce y otros vs. Barbados", Sentencia sobre Excepción Preliminar, Fondo, Reparaciones y Costas, 20 de noviembre de 2007, Serie C, N 169, párrafo 78.

48 Abregú, Martín y Courtis, Christian. «Perspectivas y posibilidades del amicus curiae en el derecho argentino». En la obra colectiva compilada por dichos autores: La aplicación de los tratados sobre derechos humanos por los tribunales locales. CELS. Buenos Aires: Editores del Puerto, 1997, pp. 392-393.

49 Corte IDH, "Caso Castañeda Gutman vs. Estados Unidos Mexicanos", Sentencia sobre Excepciones Preliminares, Fondo, Reparaciones y Costas, 6 de agosto de 2008, Serie C, Nº 184, párrafo 14.

${ }^{50}$ Cabe recordar que en su momento había juzgado que tales escritos podían ser presentados en cualquier momento antes de la deliberación de la sentencia correspondiente (Corte IDH, "Caso Kimel vs. Argentina", Sentencia de Fondo, Reparaciones y Costas, 2 de mayo de 2008, Serie C, № 177, párrafo 16); entendiendo también que, conforme a su práctica, los amici pueden incluso referirse a cuestiones relacionadas con el cumplimiento de la sentencia (Corte IDH, "Caso Castañeda Gutman vs. Estados Unidos Mexicanos", cit., párr. 14).

51 Corte IDH, “Caso Castañeda Gutman vs. Estados Unidos Mexicanos”, Ibídem.

52 Cfr. Trionfetti, Víctor, Ob. Cit., p. 76.

53 Ibídem, p. 69.

54 Carrió, Genaro. «Una Defensa Condicionada de la Judicial Review». AA.VV. Fundamentos y Alcances del Control Judicial de Constitucionalidad. Cuadernos y Debates. $N^{\circ} 29$. Madrid: Centro de Estudios Constitucionales, 1991, p. 162.

55 Así lo ha dejado plasmado la posición mayoritaria del Tribunal en la citada Acordada $N^{\circ}$ 28/2004 que instrumentara la figura.

${ }^{56}$ Nino, Carlos S. Fundamentos de Derecho Constitucional. Análisis Filosófico, Jurídico y Politológico de la Práctica Constitucional. Buenos Aires: Astrea, 1992, p. 696.

57 Cfr. supra, en nota 51. 